\title{
Communication, Gender and Formality: A Study of Request Forms Used by Undergraduate Students in Ghana
}

\author{
Philip Arthur Gborsong \\ Department of Communicative Studies, University of Cape Coast, Cape Coast, Ghana \\ Email: pgborsong@yahoo.com
}

Received 6 February 2016; accepted 20 March 2016; published 24 March 2016

Copyright @ 2016 by author and Scientific Research Publishing Inc.

This work is licensed under the Creative Commons Attribution International License (CC BY).

http://creativecommons.org/licenses/by/4.0/

(c) (i) Open Access

\begin{abstract}
The question of sex difference in communication has been a growth industry as scholars have attempted to claim and to counter claim that there are or are not important differences in the ways in which males and females communicate. In this work, an attempt is made to find out if male and female students make requests differently. The study considered the sentence types used by males and females, the levels of formality in request making, the variety of English used, and the politeness of the requests made. Using the Speech Act Theory of Austin and Searle, and the Convergence theory in Gender as a theoretical base, an argument is made that females and males make requests differently. A major finding was that the interrogative was the most commonly used sentence type in making requests especially by females; the males used imperatives more often than the females. In instances where declaratives were used, it was observed that males used simple declarative sentences whereas the females used complex declarative sentences.
\end{abstract}

\section{Keywords}

Communication, Gender, Formality, Requests

\section{Introduction}

Requests are face-threatening acts (FTA). A face-threatening act is a universal aspect of language use which infringes on the hearer's need to maintain his/her self-esteem and be respected (Brown \& Levinson, 1987). Requests are, thus, associated with politeness. Lakoff $(1973 \mathrm{a}, \mathrm{b})$ identifies three politeness principles for the maintenance of face or relationships in communication. These are: Do not impose, give options and make your listener feel good. Lakoff's principles have the aim of being polite to one's audience in communication. This is 
relevant to the study as we will look at the politeness in the structures made by subjects for our data and analysis concentrating on the presence or absence of please in this research with reference to Lakoff's principles. Since politeness seems to deal with a future act by the addressee, the politeness of the request also determines the level of familiarity between the interlocutors. Thus, formality comes into play here. There are three hierarchical relationships which can be described as "superior to", "inferior to" and "equal to" and a non-hierarchical relation described as "get close to", "keep at arm’s length” and "be approachable” (Sekyi-Baidoo, 2002).

Requests occur between at least two people and are realized by the use of a variety of communicative forms like declaratives, interrogative and imperatives. There are various factors that affect the way we make requests. These include the age difference, socio-economic background, educational background and gender. For the purpose of this research, we looked at the influence of gender on requests. University of Cape Coast (UCC) is a multilingual community and, therefore, the skill to interact is crucial because not all interactions are carried out in Standard English. Taking some Ghanaian languages as example, Akan, Ga and Ewe are often used informally where participants share a common Ghanaian language. Sometimes, in informal situations especially among male students, as noted by Sackey (1997), Pidgin English, a popular code among young university students, is used.

Some studies have focused on request expressions and the use of requests in second language acquisition and how learners produce request expressions (Mizuno, 1996; Kasper \& Rose, 1999; Achiba, 2003; Anderson, 2005). I choose to study requests because there have not been many studies of this speech act in the University of Cape Coast. Similarly, studies in gender and language are few in the university (Gborsong, 2001, 2008, 2009; Prah, 2002).

\subsection{Purpose of the Study}

As stated earlier, a few studies have been carried out concerning gender and communication: Coates (1989), Cameron (1985), Lakoff (1975), and Gborsong (2001, 2008, 2009). In this work, I intended to discover if male and female students communicated requests differently. This was to be carried out considering the sentence type used by males and females, the levels of formality in request making, the variety of English used, and the politeness of the requests made.

\subsection{Research Question}

The following questions are proposed for the study:

1) Does gender influence the use of sentence types in request making among undergraduate students in the University of Cape Coast?

2) If it does, how?

\section{Literature Review and Theoretical Framework}

One of the most intriguing areas in sociolinguistic study is communication and gender. The study of language in relation to gender has two main foci (Gborsong, 2001). The first one is the contentious claim by some sociolinguists that men and women speak differently and the second, which has been observed by some feminists and linguists, is that men and women are spoken about differently in their use of language, a situation that appears to be discriminatory against women. This study deals with both foci. However, the emphasis will be on the first focus since it is a communication issue and is relevant to this research.

Most feminist discussions about language crucially depend on the notion that language creates an imbalance in the kind of things that men and women wish to express (Philips et al., 1987). Gender is seen as intertwined with social values and, thus, denigrates and oppresses women and men. A growing number of scholars have attempted to prove that there are important differences in the way men and women communicate using the medium of English (Sellers, 1991). Robin Lakoff (1975), for instance, believes that women and men use language differently. The vocabulary used by both women and men differ. It is widely believed that women have larger colour vocabulary than men. Jesperson (1922) had previously discussed the language of Caribbean of the small Antilles, in which about one tenth of the vocabulary is different for women. The differences occurred primarily in kinship terms, names for parts of the body, and also in isolated words such as joy, work, poison and earth. In Koasati, an American Indian language (Haas, 1994), men and women's speech differs in some forms of verbal 
paradigms. It was observed that women have more extensive colour vocabularies than men.

Tannen (1990, 1994, 1998) conducted extensive research on language and gender and almost all her studies reveal that there is indeed difference in the language choice between men and women. In her book, Gender and Discourse, Tannen (1994) makes the point that communication is vital for a woman as it improves her esteem and at the same time proves her involvement in a particular culture. Discourse for women is a source of feminine leadership, and the differences in the way a woman talks with a man and vice versa reveals relationships of power and/or group (cultural) cohesion to the speakers involved. Hence, identifying gender-specific patterns of communication could allow one, whether woman or man, to recognize which conversations aim for domination from those that do not intentionally result in miscommunication. This idea then could guide one into choosing the appropriate mode of speech depending on the kind of conversation that he/she is presently involved in.

Tannen further, in her article I'll explain it to you: Lecturing and listening proves that there is strong evidence that male and female conversational patterns differ significantly. Tannen assessed the findings of other professors including Aries, Fox and Pellegrini to draw this conclusion. In small groups she set up, Aries found out that college women did talk more than college men. The men tended to set the agenda by offering opinions, suggestions and information. The women tended to react, offering agreement or disagreement. Fox's observation corresponds to Aries. That is, men are more comfortable than women in giving information and opinions and speaking in an authoritative way to a group, where as women are more comfortable than men in supporting others. Pellegrin's study shows that many men are inclined to working for social status and they challenge the authority of others.

Macaulay (1998) writes in his article, Sex Differences, that it would be surprising if there were no differences between men and women. Both men and women will use the forms of language registers and styles appropriate to the activities in which they are engaged, to the extent that these activities differ between males and females. Thomson (2006) agrees to Macaulay's point of view and argues that the stereotypical nature of the topic being discussed will influence gender-preferential communication. He examined the language used in discussion groups online in female-stereotypical discussion lists and these included items like, fashion, health and shopping; male- stereotypical discussion lists included items like sports, cars, and computers and gender neutral discussion lists items like music, films, and television. He found out that participants displayed linguistic features appropriate for the stereotype of the particular logic.

Yet another important study is of Jesperson (1998). He sets out to investigate the essential difference between the speech of men and women that can either be attributed to some discriminating kind of socialization or even better, to genetic disposition. This can be seen in many references to sex differences in language development. He claims that girls learn to talk earlier and more quickly than boys and that the speech of girls is more 'correct' than that of boys. Prof. Dorothea McCarthy stands on the same pedestal with Jesperson and she is convinced that girls are more advanced in their speech than boys. She chose to interpret the evidence as the most consistent finding to emerge from the mass of data accumulated on language development in American white children. In the data, there seems to be a slight difference in favour of girls in nearly all aspects of language that have been studied.

\subsection{The Speech Act Theory}

The speech act theory was first formulated by the philosopher, John. L. Austin in a series of lectures which are now collected into a short book with a deceptively simple title of "How to do things with Words" (Austin 1962). These ideas were further developed by another philosopher John Searle (1969, 1975), who both added to them and presented them more systematically. It has been developed by other thinkers, but for the purpose of clarity, they will be treated as a single body of thought. The theory focuses on the communicative function that a particular sentence has when it is uttered, or the "act" that it performs. It is possible to identify sentence types on the basis of their syntactic structure. For instance, there are statements, interrogative sentences, imperatives and exclamations. These correlate with the acts of giving information, asking questions, giving orders and exclaiming. However, statements or interrogatives etc., can be used to perform several other functions. That is the concern of the theory.

\subsection{The Convergence Theory}

The Convergence theory is one that brings together aspects of the Dominance theory and the Difference theory. 
Some scholars believe that language is male dominated and that women are powerless (i.e. The Dominance or Deficit Theory). Others also believe that there are differences in the way men and women use language (The Difference theory) and yet, others reject these two dimensions stating that men and women can use language interchangeably and it all depends on the context and other factors that will determine the way men and women will use language.

Although both the Dominance and the Difference theories brought about basic changes concerning the problem of gender differences, it soon turned out that neither of the two theories mentioned above managed to paint a full picture of what is going on in real life. If the Dominance theory was criticized by representatives of the Difference theory, this in turn, was further criticized by scholars expecting a broader view. According to Judit, the heaviest critique on the Difference theory was expressed by Uchida, stating that the notion of men and women belonging to different cultures is too simplistic to account for everything that occurs in mixed-sex conversation and also the dichotomization of power and culture as two separate independent concepts is inappropriate, because social interaction always occurs in the context of a patriarchal society. Uchida argues that although the intention to dominate might not exist, the fact of dominance still does. Instead of a cross-cultural view, Uchida proposes an intercultural one, which is dynamic; consisting of adapting, negotiating and creating new meanings in which you can take the other's perspective and modify the rule accordingly. She also suggests that the notions 'gender', 'power' and 'subculture' should be intertwined, and difference and dominance should simultaneously compose the social construct of gender in order to get a holistic, multidimensional view of the problem.

Freed (1995) recognized the need to reconsider the two models in relation to one another, because neither the dominance nor the difference approach alone provides an adequate explanation of the real-life facts. She observed three main trends in the gender research: a move towards multicultural comparisons; a realization that the specific culture and situational context of a communicative act must always be considered and gender itself needs to be re-evaluated. We considered the three waves of gender theories relevant to our study as we would find if any of the theories would apply to students' requests in the university community; however, we were more concerned with the Convergence theory. This enabled us to start the study on a neutral view than males and females are equal.

\section{Research Design, Instrument, Sampling and Data Collection Procedure}

The group was made up of two hundred students: one hundred and eight males and ninety-two females. These were sampled from the various schools and faculties in the university. We employed a Discourse Completion Test (DCT) because it usually provides a reliable measure of students' achievement and can also minimize guessing. The DCT comprised two sections. The first section comprised three items: the gender; age range; and the programme being pursued by the student. The second section is composed of six different settings: in the lecture hall; in the residence//hostel; in the cafeteria; in the bank; in the church and; in the library. There were fifteen contexts in all. There were also fifteen items which represented the levels of formality. The respondents or students were to rate the scenarios according to the levels of formality, which were very informal; informal;

formal; very formal; and not certain. Respondents were required to react to all the contexts.

The students were made to sit in one lecture room. The DCT was distributed among them by the researcher and his assistants. Respondents wrote what their oral requests form would be to each situation posed. They were asked to write their responses to match, as closely as possible, what they might actually say. Completed forms were collected by the researcher.

\section{Findings}

We analyzed and discussed the outcome of the data collected to see if there were any differences in the way males and females communicate requests. The variables used are; the sentence types used in making requests by males and females; the level of formality of the requests made; the variety of English used (whether it is standard or pidgin); and the politeness of the requests made. As a result of the broadness of the subject matter being covered, we selected ten situations out of the fifteen contexts presented in the DCT. Some of the contexts are similar and yield similar results so we have grouped them as like terms and selected one of such contexts for our discussion. 


\subsection{Sentence Type: Declaratives, Interrogatives, and Imperatives}

Students made requests using declarative, interrogative and imperative sentences according to our DCT. Declaratives were not used as often as interrogatives and imperatives; however, requests made in context 1 , scenario 1 revealed results which contrasted our usual findings. The context demanded that the students excused themselves in a queue at the bank to receive a phone call. Requests made in this context have been cross tabulated as below:

From Table 1, we realize that all the seventy-three students made requests using the declarative. Out of this number, forty-eight respondents constituting $65.8 \%$ were males and twenty-five were females also constituting $34 \%$ of the total number of students who made request using the declaratives. The males used declaratives such as:

Please, I will be back.

I will be with you in a jiffy.

Charlie, I dey your back.

The females also used declaratives such as:

Please, I want to get my call; I will be with you soon.

Please, I am behind you I want to receive a call outside.

I am still in the queue, I will be right back.

We realized that females used more compound sentences than their male counterparts. The males simply asked their colleagues to keep their position in the queue for them without giving any details for their being excused. Females, on the other hand, gave reasons for their being excused from the queue. Some made it clear that they wanted to receive a phone call; that was their reason for being excused. Some females also used compound sentences made up of declaratives and interrogatives as for example are:

I have to make a call, could you, please, keep my place for me?

Could you, please, reserve my place for me? I have to receive a call outside.

In context 2 scenario 1, students were to request for the repetition of an announcement given from their worship centre from their best friends and the findings of the requests made are worth discussing. The data is summarized in the table below.

From Table 2, we notice that out of the total number of students who made requests, 53 males representing $58.2 \%$ made requests using the interrogative and 38 females representing $41.8 \%$ made requests using the interrogative. Both males and females used the yes/no interrogative and the wh-interrogative in making requests. From males, we had requests such as:

What was the announcement?

What them talk?

What did he say?

Please can you tell me what was said?

Table 1. Sentence type (declaratives).

\begin{tabular}{|c|c|c|c|c|}
\hline \multirow{2}{*}{ Sex of Respondent } & \multicolumn{3}{|c|}{ Sentence Type } & \multirow{2}{*}{ Total } \\
\hline & Declarative & Interrogative & Imperative & \\
\hline \multirow{2}{*}{ Male } & 48 & 4 & 6 & 58 \\
\hline & $65.80 \%$ & $40 \%$ & $35.30 \%$ & $58 \%$ \\
\hline \multirow{2}{*}{ Female } & 25 & 6 & 11 & 42 \\
\hline & $34.20 \%$ & $60 \%$ & $64.70 \%$ & $42 \%$ \\
\hline \multirow{2}{*}{ Total } & 73 & 10 & 17 & 100 \\
\hline & $100 \%$ & $100 \%$ & $100 \%$ & $100 \%$ \\
\hline
\end{tabular}


The females also used interrogatives, and it was observed that the females used more of the yes/no interrogative than the males. We had such requests from females as:

Please did you by chance hear what was said?

Excuse me did you hear that?

Students were again asked in context 3, scenario 1 to ask their colleagues who entered the library without closing the door to do so. The summary of the outcome is represented in the Table 3 below.

As we can see in Table 3, eighty-one students (i.e. 100\%) respondents made requests in the imperative. Fortyfive students constituting $55.6 \%$ were males; the rest were females. Only one male constituting $25 \%$ and three female subjects constituting $75 \%$ made request in the declarative and twelve males constituting $80 \%$ and three females constituting $20 \%$ also made requests in the interrogative. The commonest form of imperative is the use of the verb phrase with the deletion of the subject. This form exhibits sternness or lack of intimacy. Requests made by the males include:

Please, close the door.

Close the door.

Charlie, the door.

The female requests were similar.

\subsection{Levels of Formality}

In this section our concentration will be on formality from the sociolinguistic point of view. Figure 1 gives a summary of students requesting for their book from a course mate who is an older person. Students were asked to rank their requests as very informal, informal, formal, very formal and not certain. Our interest was to find out if males and females make requests differently when the distance in age of their addresser is considered and if it affects the level of formality. The results are represented in the figure below:

Table 2. Sentence type (interrogative).

\begin{tabular}{ccccc}
\hline \multirow{2}{*}{ Sex of Respondent } & & Sentence Type & & Total \\
\cline { 2 - 5 } Male & Declarative & Interrogative & Imperative & 58 \\
& 2 & 53 & 3 & $58 \%$ \\
Female & $66.70 \%$ & $58.20 \%$ & 3 & 42 \\
& 1 & 38 & $50.00 \%$ & $42 \%$ \\
Total & $33.30 \%$ & $42 \%$ & 6 & 100 \\
& 3 & $100 \%$ & $100 \%$ & $100 \%$ \\
\hline
\end{tabular}

Table 3. Sentence type (imperatives).

\begin{tabular}{|c|c|c|c|c|}
\hline \multirow{2}{*}{ Sex of Respondent } & \multicolumn{3}{|c|}{ Sentence Type } & \multirow{2}{*}{ Total } \\
\hline & Declarative & Interrogative & Imperative & \\
\hline \multirow{2}{*}{ Male } & 1 & 12 & 45 & 58 \\
\hline & $25.00 \%$ & $80 \%$ & $55.60 \%$ & $58 \%$ \\
\hline \multirow{2}{*}{ Female } & 3 & 3 & 36 & 42 \\
\hline & $75.00 \%$ & $20 \%$ & $44.40 \%$ & $42 \%$ \\
\hline \multirow{2}{*}{ Total } & 4 & 15 & 81 & 100 \\
\hline & $100 \%$ & $100 \%$ & $100 \%$ & $100 \%$ \\
\hline
\end{tabular}




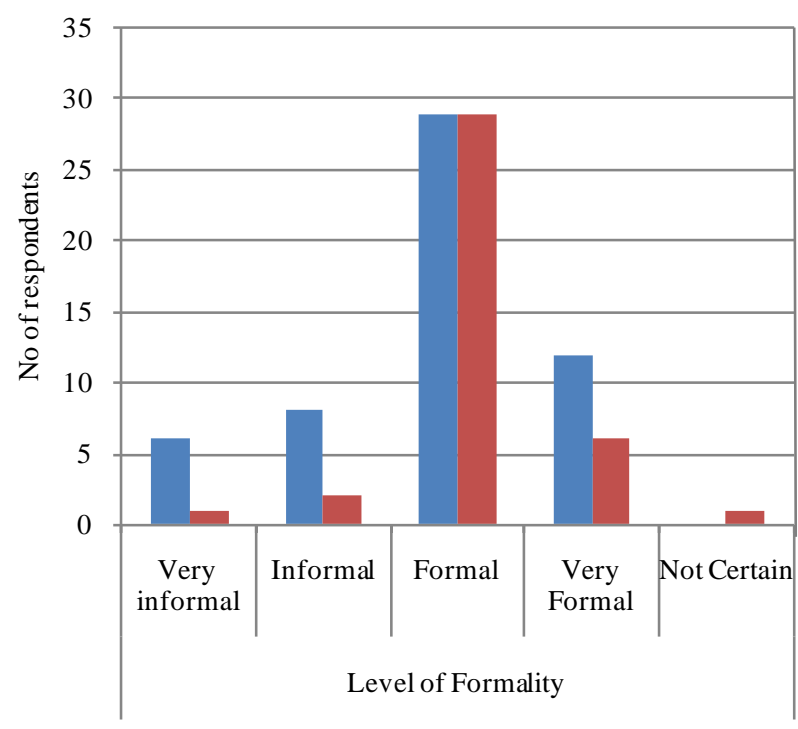

- Sex of Respondant Male Count

- Sex of Respondant Female Count

Figure 1. Level of formality-asymmetrical.

As we can see in Figure 1, six males rated their requests as very informal as against one female. Eight males and two females rated their requests as informal. Twenty-nine males and twenty-nine females rated their requests as formal. Twelve males and six females said their requests were very formal. Only one female was not certain of the level of formality. We realize from the above results that age difference is considered when it comes to formality. The majority of males and females rated context 1 , scenario 2 as formal. Males' requests include the following:

Please, I need my book. (Formal)

Please, may I have my book? (Very Formal)

Mr. Mensah, you get my book? (Informal)

Females' requests also include:

Please, can I have my book back? (Formal)

Auntie Bee, please, can I have my book? (Formal)

We realize that both males and females rated the context as formal. Seventy-two percent of respondents with age range between eighteen and twenty-four constituting the majority of students who completed the DCT did similar rating. We can say that most of the students who rated the context as formal fall in this group and that is an indication that both males and females make requests taking into consideration the age difference between themselves and their interlocutors.

In context 4 scenario 1 students were asked to request for their marked assignment from their course representative, Elizabeth (a female). We wanted to find out if males and females would react differently to this context when the addressee is a female.

As seen in Figure 2, nine males and nine females said the context was very informal. Seventeen males and sixteen females rated the context as informal. Twenty-six males and thirteen females rated the context as formal. Four males and two females said the context was very formal. Two male respondents were not certain of the level of formality. The results show that the male respondents were more than the females who rated the context as formal. Some of the males' requests are as follows:

Elizabeth, I've not got mine. (Informal)

Elizabeth, did you see any marked paper with the registration number ... (Formal)

The females' requests also include:

Could you please check to see if my paper is mixed up with others? (Formal)

Is my assignment lost? (Very Informal) 
The results indicate that males are more formal when the addressee is a female. Let us look at another context where the addressee is a male and compare the results to see if there would be any different results in contrast to the former.

In context 2, the place of interaction is the hall/hostel of residence. Students were asked to request for some vegetable from their roommate. All first years in the University are supposed to be accommodated in the halls. However, a few students may decide to stay in hostels, so we presume that the respondents who completed the DCT have their year mates as roommates. The results of respondents are as follows: thirteen male respondents out of the total number of fifty-seven saw the context as very informal; six female respondents out of the total number of forty-two saw it as very informal; eighteen male respondents and eighteen female respondents said it was informal; eighteen male and fourteen female respondents rated it as formal; five male and three female respondents rated it as very formal; and three males and one female respondent were not certain of the level of formality. Some of males' ratings are as follows:

I beg you no get some tomatoes? (Informal)

I beg boy, you have some tomatoes for there? (Very Informal)

Ofori, kindly give me some onion. (Formal)

This is shown in Figure 3.

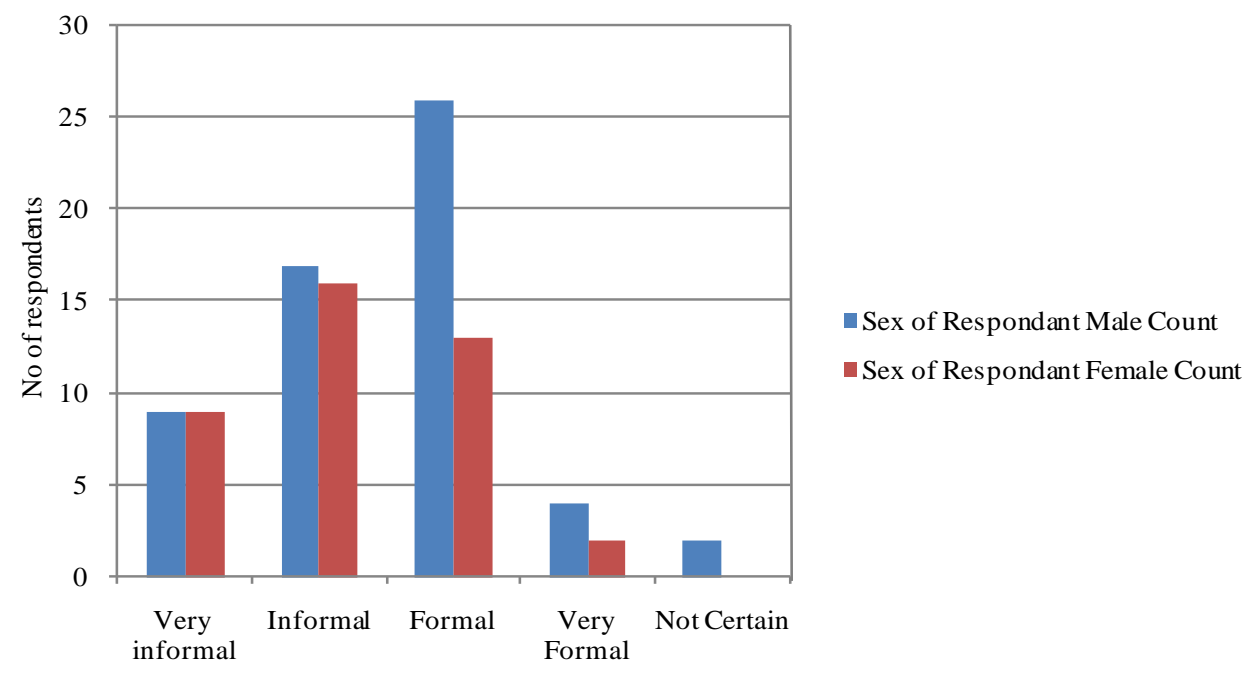

Figure 2. Levels of formality (symmetrical 1).

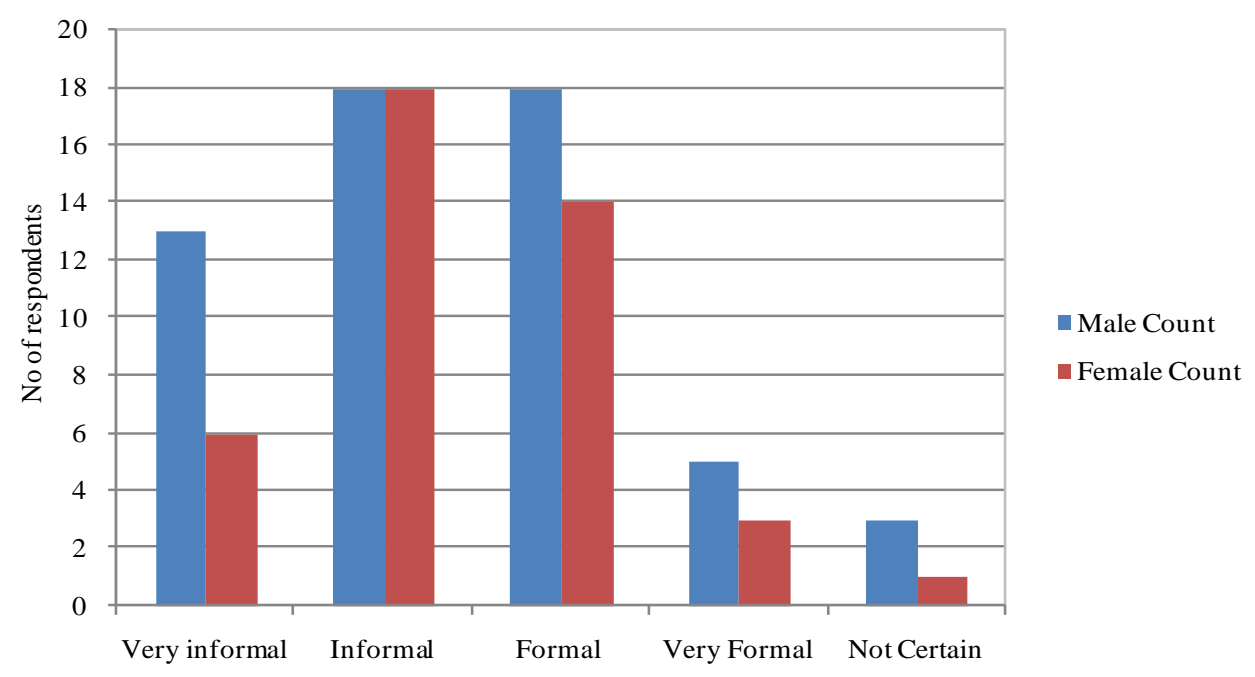

Figure 3. Levels of formality (symmetrical 2). 
Examples of the ratings by the females are:

Can I have some tomatoes? (Very Informal)

Do you mind if I use your onions? I am short of some. (Informal)

Please, can you lend me some tomatoes? (Very Formal)

Even though most of the males and females' requests were informal, it can be noted that the males used pidgin English and nicknames like "Charlie", "Pattoe", "Bros" showing intimacy between interlocutors. The females used Standard English and endearment terms such as "Sweetie", "Baby", "Dear" in showing intimacy between them and their interlocutors. We can say that both males and females used different words in showing intimacy and solidarity as stated by Herbert (1990). Comparing the results of context 1 scenario 3 and context 2 scenarios 4, we can see that females retain some level of formality regardless of their interlocutors' gender and the place of interaction. The level of formality rises when the male's interlocutor is a female and drops when the interlocutor is a male, and when males move from the lecture hall to their halls of residence.

\subsection{Standard/Non-Standard (Pidgin) English}

Students also used Standard British/American English and Non-Standard British/American English in communicating requests. We observed that the males used Pidgin English more frequently than the females. There were only a few instances that females used it. The Table 4 below presents the variety of English Spoken (in context 2). Students were supposed to request assistance from their friends to carry a luggage to their rooms.

As seen in Table 4, twenty males constituting $90.9 \%$ and only two females constituting $9.1 \%$ within the group that spoke Pidgin English spoke Pidgin English. Thirty-eight males constituting $48.7 \%$ and forty females constituting 51.3\% used Standard English in making requests. Pidgin English spoken by the male respondents include:

I beg, make you help me carry my luggage.

Charlie, help me, we go inside.

Charlie, you go fit help make I wey ma nibbles go room.

Examples of Standard English used by males in making requests are as follows:

Please, kindly help me.

James, please give me a hand.

Below are also examples of females' requests. The first two examples are Standard English and the latter two examples are Pidgin English:

James, can you help me with my luggage?

Please, help me with my luggage.

Aaba, Brother James, make you come assist me ooh, I beg.

Charlie, make you be my boy, boy for just a minute ok.

Table 4. Variety of English spoken in the halls of residence.

\begin{tabular}{|c|c|c|c|}
\hline \multirow{2}{*}{ Sex of Respondent } & \multicolumn{2}{|c|}{ Variety of English Spoken } & \multirow{2}{*}{ Total } \\
\hline & Pidgin English & Standard English & \\
\hline \multirow{2}{*}{ Male } & 20 & 38 & 58 \\
\hline & $90.90 \%$ & $49 \%$ & $58 \%$ \\
\hline \multirow{2}{*}{ Female } & 2 & 40 & 42 \\
\hline & $9.10 \%$ & $52 \%$ & $42 \%$ \\
\hline \multirow{2}{*}{ Total } & 22 & 78 & 100 \\
\hline & $100 \%$ & $100 \%$ & $100 \%$ \\
\hline
\end{tabular}


The use of Pidgin English in the two instances by the females could only explain the level of familiarity that these ladies are with James. This can be seen in the address forms used.

In the first instance, it could be that both interlocutors belong to the same fraternity group, hence the use of the address term, "Brother James". The second instance shows the intimacy that exists between the female and James. The female probably knows that James will not be offended by the statement "be my boy, boy". We can draw from the above results that females used Standard English more often in informal settings such as in the hall of residence than males. Let us find out if the same results will occur in a formal setting such as in the bank. In context 5 , scenario 1 , students were supposed to ask for assistance in filling a form at the bank and it was observed that eleven male students constituting 100\% spoke pidgin. That is, no female student spoke Pidgin English. Forty-seven males constituting $53.4 \%$ and forty-one females constituting $47 \%$ within the group who spoke used Standard English. One female respondent did not fill this section. This is shown in Table 5.

The results show that students used Standard English when they were in the bank. Their requests were also more polite when compared to context 2, scenario 1 . Both situations demanded that respondents request for help from their colleagues. Some of the requests made by the male respondents at the bank are as follows:

Please, may I get a helping hand?

Please, help me fill this form.

Boss Boss, make you help me fill this form.

The first two are Standard English and third example is Pidgin English. Below are examples of females' requests. Both requests are Standard English as shown below:

Please, help me with these forms; I don't understand.

Please, Mary, I was late help me to fill the form.

Students speak Standard English more often when they are in a formal setting than when they are in an informal setting. Male students speak Pidgin English in informal settings more often than in a formal setting and females use Pidgin English when the level of familiarity between their interlocutors and themselves is high.

\subsection{Politeness Presence/Absence of Please}

We will concentrate on the politeness marker, please. We looked at the presence or absence of please in requests made by students to find out if there is any gender differentiation in the making of requests. We present a situation where students are supposed to request for their rice cooker from a friend. The discourse takes place in the hall of residence or hostel. Fifty-four male and forty female respondents did not use the politeness marker please in their requests. Four male and two female respondents used please in making their requests.

As seen in the Figure 4, ninety-four out of hundred students made requests without saying please. Out of this number, fifty-four were males and forty were females. Even though this context recorded the highest number of the absence of please, there were other forms of politeness markers used by respondents. It was, however, observed that the female respondents used the other forms of politeness markers such as "may I", "can I", "I beg". Some went further to explain the reason why they needed the rice cookers. This is another form of politeness. In sentences like:

Table 5. Variety of English spoken in the bank.

\begin{tabular}{|c|c|c|c|}
\hline \multirow{2}{*}{ Sex of Respondent } & \multicolumn{2}{|c|}{ Variety of English Spoken } & \multirow{2}{*}{ Total } \\
\hline & Pidgin English & Standard English & \\
\hline \multirow{2}{*}{ Male } & 11 & 47 & 58 \\
\hline & $100.00 \%$ & $53 \%$ & $58 \%$ \\
\hline \multirow{2}{*}{ Female } & 0 & 41 & 41 \\
\hline & $0.00 \%$ & $47 \%$ & $41 \%$ \\
\hline \multirow{2}{*}{ Total } & 22 & 88 & 99 \\
\hline & $100 \%$ & $100 \%$ & $99 \%$ \\
\hline
\end{tabular}




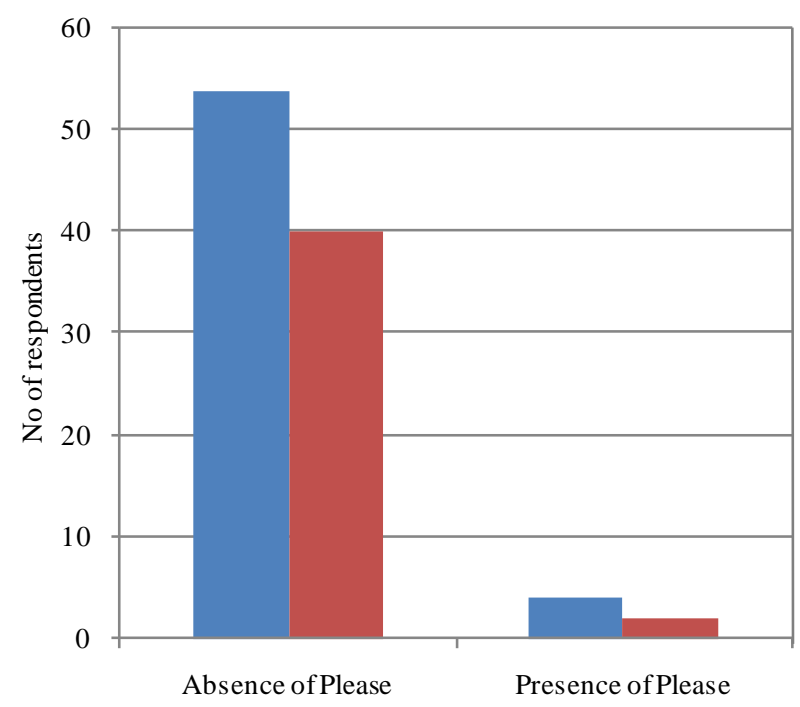

- Sex of Respondant Male Count

- Sex of Respondant Female Count

Figure 4. Absence/presence of please (in the halls of residence).

Can I get my rice cooker, I need to cook rice.

Richard, this is the last time I'll give my rice cooker to you. Let me have it.

Borrower, return my rice cooker, please, oh!

HIPC boy! Just return my rice cooker now, now, now, please.

I beg, give me my rice cooker. Next time try to return it.

We realized that in the instance where please is not used to show politeness, the use of the address terms, "Borrower" and "HIPC boy" makes the use of please in the requests sarcastic. The speaker shows familiarity instead of politeness.

The pattern of the male respondents is slightly different. There were few cases where the respondents used "can I" and "I beg” which were used in Pidgin English. Examples of respondents' requests are:

Richie, you no finish with my rice cooker?

Charlie, where my rice cooker dey?

I beg, I go fit get my rice cooker?

You, borrower, return my rice cooker now.

Richard are you through with my rice cooker, I want to cook.

From the examples above, we can say that one difference is that the male respondents used Pidgin English in the halls of residence among themselves. Some students are more polite and the use of "please" here is genuine unlike the female respondents whose use of "please" was sarcastic.

The following took place at the cafeteria. Students were to request for money from their colleagues to pay for their meals. From the figure below it can be seen that more female respondents used the politeness marker please than the male respondents.

From Figure 5, it can be seen that, out of the total of forty-nine respondents, thirty males requested for money from their friends without using please. The rest were females. Twenty-eight males requested for money using please and twenty-three females also used please. Some of the requests of the males are:

Please, am broke, can you give me some money to settle my bills?

You go feel help me settle the debt, my money no go catch.

Oh! Charlie, I don't have money.

Please do you have some money on you? I need five cedis; I've forgotten my money in the hall.

Apart from the use of the phrase "can you", the above responses are worth discussing. The female responses include:

Please, Ama, can I have some money? 


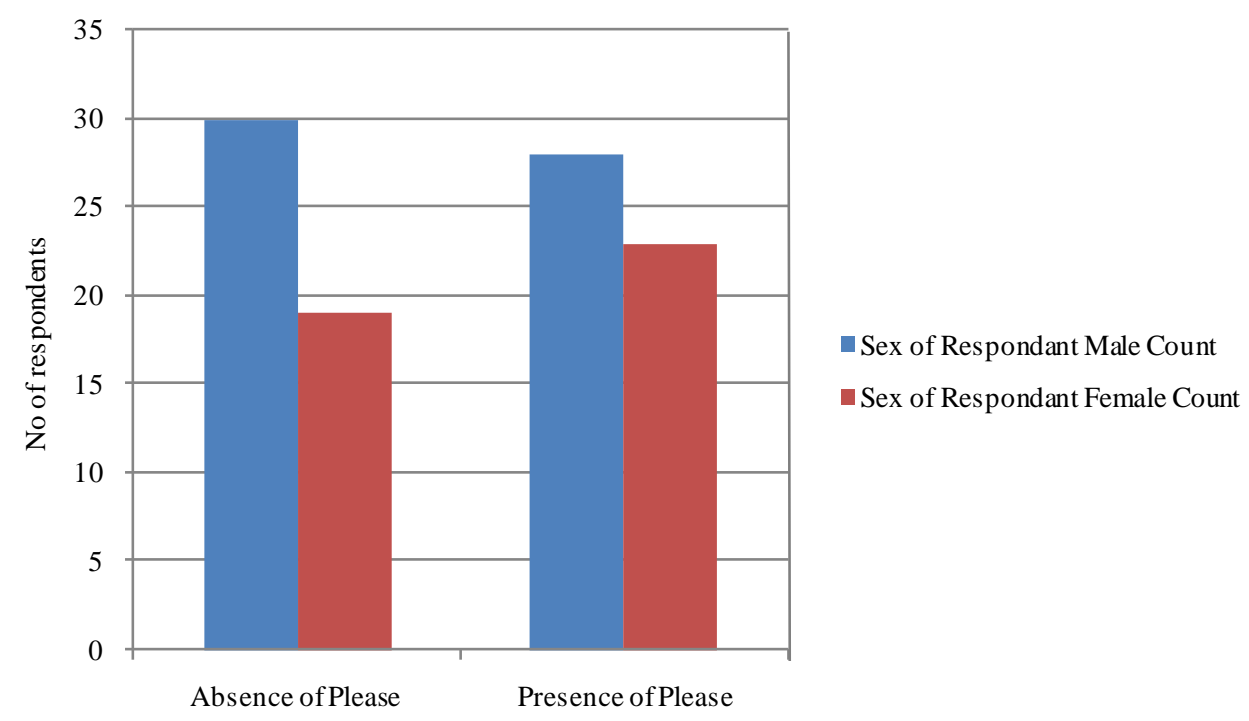

Figure 5. Absence or presence of please (in the Cafeteria).

My money is missing; Theo, can I get one cedis to settle my bill?

Kate, can I get some money? I'll give it back when we get to the hall.

From the discussion, we can say that females used more polite terms even though they did not use "please" in their requests. There was the presence of some forms of politeness markers such as "can you", "could you" and "kindly". The males did not use such phrases in their sentences as the females did.

\subsection{Summary of Findings}

To begin with, it was evident from the research that gender influenced requests. Males and females made requests differently. We noted that the interrogative was the most commonly used sentence type in making requests especially by females; the males used imperatives more often than the females. In instances where declaratives were used, we observed that males used simple declarative sentences whereas the females used complex declarative sentences. The males also used the wh-interrogatives and the females used the Yes/No interrogative sentences. There was no striking difference between males and females' use of imperatives in making requests. On the whole, females used interrogative sentences more often than their male counterparts, and the males also used all the three forms of sentence types in making requests.

The research also reveals that the gender of the addressee and the place of interaction affect request making. For females, the level of formality is retained regardless of the two factors stated above whereas for males, the gender of the addressee and place of interaction are considered important. When the addressee is a male, the level of formality drops and when the addressee is a female, the level of formality rises. Also, the males show more formality in formal settings than they do in informal settings. Males tend to use non-Standard English and this reduces formality.

Another interesting finding is that males use non-Standard English (Pidgin English) in making requests in formal settings when their addressees are males and females use Pidgin English when the level of familiarity between their interlocutors and themselves is very high.

Finally, it was observed that females made more polite requests than males, but there were instances where the use of the polite marker, please, was found to be sarcastic. This happened when someone came for ladies' items and did not return it and they had to confront the person for their item.

\subsection{Implications}

The findings have implications that are related to communication and gender. First, the study reveals that whereas females are likely to use compound sentences in making requests, males are likely to use simple sentences. Also, females are likely to display some degree of social distance in both formal and informal contexts 
where males are likely to display some level of formality when the addressee is a female and informality when the address is a male.

Moreover, males are likely to use Non-Standard English forms in both formal and informal setting; however, Standard English may be used more in formal settings. Females, on the other hand, used Standard English in both formal and informal settings; Pidgin English may be used (especially by males) when there is a high level of familiarity between females and their addressees. Lastly, females are likely to be more polite than males in request making. The frequent use of politeness markers by females shows some level of distance whereas the absence of polite markers in males' requests shows intimacy.

\subsection{Suggestions}

The level of distance shown by females in their request making is evident in this study. The male respondents were more outspoken as compared to the female respondents. There seems to be more males than females and so the males seem to overshadow the females. We suggest that the University admit a balanced intake of males and females. Males should also be discouraged from speaking Pidgin English as this might affect their English in academic communication.

Males and females are to be encouraged to perform group tasks together. This will reduce the frequency at which males speak Pidgin English and will help them improve their English. The group interaction will help females open up to males and other females to encourage effective communication among them.

\subsection{Conclusion}

All in all, this paper has examined the use of request forms among students of tertiary institutions in Ghana by using the University of Cape Coast as a case study. It is the only paper that has looked at gender in requesting. Also, it is the only work that considers the issue of formality in the use of requests. Therefore, it stands to be, probably, significant in its contribution to the study of request forms universally.

\section{References}

Achiba, M. (2003). Learning to Request in a Second Language: A Study of Child Interlanguage Pragmatics. Clevedon: Multilingual Matters.

Brown, G., \& Levinson, S. (1987) Politeness: Some Universals in Language Usage. Cambridge, MA: The MIT Press.

Cameron, D. (1985) Feminism and Linguistic Theory. London: Macmillan. http://dx.doi.org/10.1007/978-1-349-17727-1

Freed, A. (1995). Language and Gender. Annual Review of Applied Linguistics, 15, 3-22. http://dx.doi.org/10.1017/S0267190500002580

Gborsong, P. A. (2001) Language, Power and Gender in Informal Conversation among Teachers and Students in Ghana. Mphil Thesis (Unpublished). Cape Coast: University of Cape Coast.

Haas, M. (1994). Men’s and Women’s Speech in Kaosati. Language, 20, 142-149.

Jesperson, O. (1922). Language: Its Nature, Development and Origin. New York: W.W. Norton \& Co.

Jesperson, O. (1998). Sex Difference in Language Development. In G. Goshgaria (Ed.), Exploring Language (8th ed.). New York: Addison-Wesley Educational Publishers Inc.

Kasper, G., \& Rose, K. (1999). Pragmatics and Second Language Acquisition. Annual Review of Applied Linguistics, 19, 81104.

Lakoff, R. (1973a). Language and Women’s Place. Language in Society, 2, 45-80. http://dx.doi.org/10.1017/S0047404500000051

Lakoff, R. (1973b). The Logic of Politeness or Minding Your P's and Q’s. Proceedings of the Ninth Regional Meeting of the Chicago Linguistic Society, Chicago, 13-15 April 1973, 292-305.

Macaulay, R. (1998). Sex Difference. In G. Goshgaria (Ed.), Exploring Language (8th ed.). New York: Addison-Wesley Educational Publishers Inc.

Mizuno, K. (1996). Differing Perceptions of Politeness between Japanese and American Learners of Japanese. Southeast Review of Asian Studies, 20, 61-80.

Philips, S. U., Steele, S., \& Tanz, C. (1987). Language, Gender and Sex in Comparative Perspective. Cambridge: Cambridge University Press. http://dx.doi.org/10.1017/CBO9780511621918 
Prah, M. (2002). Gender Issues in Ghanaian Tertiary Institutions: Women Academics and Administrators at Cape Coast University. Ghana Studies, 5, 83-122.

Sackey, J. A. (1997). The English Language in Ghana, Historical Perspective. In M. E. Dakubu (Ed.), English in Ghana (pp. 33-45). Accra: Black Mask Publishers.

Searle, J. (1969). Speech Acts. Cambridge: Cambridge University. http://dx.doi.org/10.1017/CBO9781139173438

Tannen, D. (1990). You Just Don't Understand Women and Men in Conversation. New York: Baltimore Books.

Tannen, D. (1994). Gender and Discourse. New York: Oxford University Press.

Tannen, D. (1998). I’ll Explain It to You, Learning and Listening. In G. Goshgaria (Ed.), Exploring Language (8th ed.). New York: Addison-Wesley Educational Publishers Inc.

Thomson, R. (2006). The Effects of Topic Discussion on Gendered Language in Computer-Mediated Communication Discussion. Journal of Language and Social Psychology, 25, 197-178. http://dx.doi.org/10.1177/0261927X06286452 


\section{SAMPLES OF DCT}

Respond to the following scenarios in the most appropriate way you think.
Sex
$\mathrm{M}$
$\mathrm{F} \square$

Put a tick $\square$ in the choice.

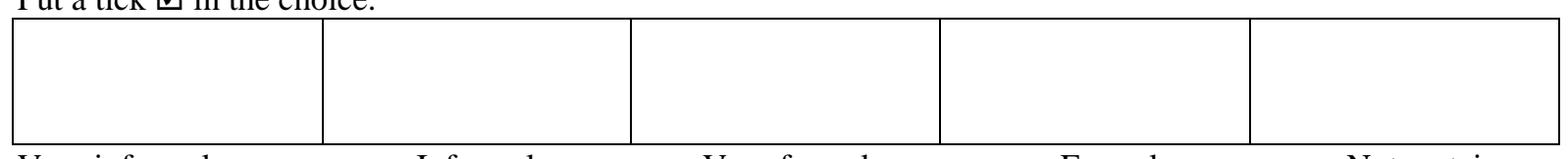

$\begin{array}{lllll}\text { Very informal } & \text { Informal } & \text { Very formal } & \text { Formal } & \text { Not certain }\end{array}$

\section{Scenario 1}

You were at a worship centre and could not hear an announcement was made.

a. You regard the context.

b. You want to ask a colleague to repeat the announcement for you. You say

\section{Scenario 2}

You are at the Ghana Commercial Bank premises to deposit money.

a. You consider the context.

b. You want a deposit form from a bank official. You say 